\title{
Patient knowledge and pulmonary medication adherence in adult patients with cystic fibrosis
}

\author{
This article was published in the following Dove Press journal: \\ Patient Preference and Adherence \\ 30 March 2017 \\ Number of times this article has been viewed
}

\author{
Ann Hsu-An Lin' \\ Jennifer G Kendrick ${ }^{2,3}$ \\ Pearce G Wilcox ${ }^{4,5}$ \\ Bradley S Quon ${ }^{4,5}$ \\ 'Faculty of Medicine, ${ }^{2}$ Faculty of \\ Pharmaceutical Sciences, University \\ of British Columbia, ${ }^{3}$ Department of \\ Pharmacy, Children's and Women's \\ Health Centre of British Columbia, \\ ${ }^{4}$ Department of Medicine, Division of \\ Respiratory Medicine, University of \\ British Columbia, ${ }^{5}$ Centre for Heart \\ Lung Innovation, St Paul's Hospital, \\ Vancouver, BC, Canada
}

Background and objectives: Patient knowledge of lung function (ie, forced expiratory volume in $1 \mathrm{~s}\left[\mathrm{FEV}_{1}\right] \%$ predicted) and the intended benefits of their prescribed pulmonary medications might play an important role in medication adherence, but this relationship has not been examined previously in patients with cystic fibrosis (CF).

Methods: All patients diagnosed with $\mathrm{CF}$ and without prior lung transplantation were invited to complete knowledge and self-reported medication adherence questionnaires during routine outpatient visits to the Adult CF Clinic, St Paul's Hospital, Vancouver, Canada from June 2013 to August 2014.

Results: A total of 142 out of 167 (85\%) consecutive adults attending CF clinic completed patient knowledge and medication adherence survey questionnaires. Sixty-four percent of the patients recalled their last $\mathrm{FEV}_{1} \%$ predicted value within $5 \%$, and $70 \%$ knew the intended benefits of all their prescribed medications. Self-reported adherence rates were highest for inhaled antibiotics (81\%), azithromycin (87\%), and dornase alpha $(76 \%)$ and lowest for hypertonic saline (47\%). Individuals who knew their $\mathrm{FEV}_{1} \%$ predicted value within $5 \%$ were more likely to self-report adherence to dornase alpha ( $84 \%$ vs $62 \%, P=0.06)$ and inhaled antibiotics $(88 \%$ vs $64 \%, P=0.06$ ) compared to those who did not, but these associations were not statistically significant. There were no significant associations observed between patient knowledge of intended medication benefits and self-reported medication adherence.

Conclusion: Contrary to our hypothesis, disease- and treatment-related knowledge was not associated with self-reported medication adherence. This suggests other barriers to medication adherence should be targeted in future studies aiming to improve medication adherence in adults with $\mathrm{CF}$.

Keywords: cystic fibrosis, health literacy, medication adherence, patient compliance, patient medication knowledge

\section{Abbreviations}

$\mathrm{CF}$, cystic fibrosis; $\mathrm{FEV}_{1}$, forced expiratory volume in $1 \mathrm{~s}$.

\section{Introduction}

Treatment guidelines for CF recommend the use of long-term oral and inhaled medications to manage pulmonary disease and improve clinical outcomes. ${ }^{1}$ Nebulized mucolytics and hyperosmolar agents to augment mucociliary clearance and inhaled and oral antibiotics to control infection and inflammation are prescribed as maintenance therapies to improve lung function and prevent pulmonary exacerbations. Despite these benefits, medication adherence among individuals with CF remains low, ranging from $33 \%$ to $76 \%$ based on pharmacy dispensing records and electronic medication monitors..$^{2-4}$ Poor adherence to medication is associated with adverse clinical outcomes in $\mathrm{CF}$. 5,6
Correspondence: Bradley S Quon Centre for Heart Lung Innovation, St Paul's Hospital, \#166 - 108I Burrard Street, Vancouver, BC V6Z IY6, Canada Tel +l 6046822344 (ext 62762)

Email bradley.quon@hli.ubc.ca 
Self-reported barriers to medication adherence reported in the literature with regard to $\mathrm{CF}$ include treatment burden, time requirement, forgetfulness, fatigue, stigma, and embarrassment. ${ }^{7-10}$ Other barriers self-reported by patients include absence of perceived benefits and doubts about the necessity of treatment. ${ }^{6,11,12}$ As such, patient knowledge is a potential determinant of pulmonary medication adherence because it influences perceived or anticipated medication benefits and the necessity of treatment. One study has found that adherence to medication is related to children's and parents' knowledge on treatment details. ${ }^{13}$ Another recent study demonstrated a potential association between CF knowledge using a validated CF knowledge scale and patient-reported treatment adherence in a post hoc analysis. ${ }^{14}$ To our knowledge, the impact of patient knowledge of lung function (ie, $\mathrm{FEV}_{1} \%$ predicted) and the intended benefits of prescribed medications on medication adherence has not been examined previously in $\mathrm{CF}$.

The objectives of this study were as follows: 1) to assess patient knowledge of their own $\mathrm{FEV}_{1} \%$ as a marker of lung disease severity and the intended benefits of maintenance pulmonary therapies, 2) to identify factors (eg, lung function, age, and sex) associated with patient knowledge, and 3) to examine the association between patient knowledge of their own $\mathrm{FEV}_{1} \%$ and intended benefits of maintenance pulmonary therapies with self-reported pulmonary medication adherence. We hypothesized that patients with less knowledge of their lung function and intended medication benefits would be less likely to be adherent with their prescribed pulmonary maintenance therapies.

\section{Methods}

\section{Study participants}

All adult patients ( $\geq 18$ years) diagnosed with CF based on standard criterion ${ }^{15}$ and without prior lung transplantation were invited to complete surveys during routine outpatient visits to the Adult CF Clinic, St Paul's Hospital, Vancouver, Canada, from June 1, 2013 to August 31, 2014. This clinic sees adult patients with CF in the province of British Columbia every three to four months. This convenience sampling over a year-long period during all outpatient visits meant that the majority of the patient population was sampled. Ethical approval was obtained from the University of British Columbia-Providence Health Research Ethics Board (UBC PHC H13-00044). Participants provided written informed consent and the survey responses were non-identifiable.

\section{Chart review}

A retrospective chart review was performed for all patients who attended the CF clinic at St Paul's Hospital following ethical approval. Sex, age, body mass index, and number of pulmonary exacerbations in the prior year were compared between the subsets of patients who did and who did not complete the survey to determine if there were any systematic differences between the two groups and to identify demographic and/or clinical factors associated with patient knowledge and medication adherence.

\section{Patient knowledge questionnaires}

Questionnaires were developed to assess patient knowledge and medication adherence. Patient knowledge of their lung disease severity (ie, lung function) was determined by asking the participant to indicate on a bar scale ranging from 0 to $100 \%$ their last measured $\mathrm{FEV}_{1} \%$ predicted value (postbronchodilator). Patients were considered knowledgeable of their own $\mathrm{FEV}_{1} \%$ if they were correct within an absolute range of $\pm 5 \%$ of their last measured $\mathrm{FEV}_{1} \%$ predicted value. Their actual last $\mathrm{FEV}_{1} \%$ was noted on a sealed envelope by the research coordinator along with their completed survey; surveys were opened in batches to preserve anonymity. Knowledge of intended pulmonary benefits of the prescribed medications, that is dornase alpha, hypertonic saline, inhaled antibiotics, and azithromycin, was assessed with the help of multiple-choice questions (Table 1). Subjects were considered overall knowledgeable of their medication benefits if they knew the intended benefits of all $(100 \%)$ the medications they self-reported to have been prescribed.

\section{Medication adherence questionnaire}

Patients self-reported their medications and adherence to each medication by answering two questions adapted from McNamara et al: "On an average week, how many doses do you miss?" and "In the past 3 months, what percentage

Table I Multiple choice options and correct answers for each drug class

\begin{tabular}{|c|c|c|c|c|}
\hline \multirow[t]{2}{*}{ Medication } & \multicolumn{4}{|c|}{ Multiple choice options } \\
\hline & $\begin{array}{l}\text { Reduction } \\
\text { in mucus }\end{array}$ & $\begin{array}{l}\text { Treatment } \\
\text { of infection }\end{array}$ & $\begin{array}{l}\text { Reduction in } \\
\text { inflammation }\end{array}$ & $\begin{array}{l}\text { Not } \\
\text { sure }\end{array}$ \\
\hline Dornase alpha & Correct & & & \\
\hline Hypertonic saline & Correct & & & \\
\hline Inhaled antibiotics & & Correct & & \\
\hline Azithromycin & & Correct* & Correct* & \\
\hline
\end{tabular}

Notes: *Either option was considered correct. Patients answered the question "What is the primary benefit of taking [medication]?", designed to assess knowledge of medication benefit. 
of your medication did you take?"16 They were considered adherent if they self-reported taking their medications more than $80 \%$ in the past three months and missing less than $20 \%$ in an average week, as commonly classified in adherence research. ${ }^{17}$ Responses that showed discrepancies between the self-reported doses missed and percentage of doses taken were considered discordant responses for that particular individual medication and excluded from the primary analysis. A sensitivity analysis was conducted evaluating the impact of classifying the discordant responses as adherent versus nonadherent for each individual medication and overall medications. Self-reported medication adherence was reported for each individual pulmonary medication and overall for all medications. Patients were considered overall adherent to their medications if they were categorized as adherent to the majority $(>50 \%)$ of their prescribed medications.

\section{Analysis plan}

Descriptive analyses were performed comparing patients who did versus those who did not complete the questionnaires. Patient knowledge of their last measured lung function (ie, $\mathrm{FEV}_{1} \%$ predicted value) and intended medication benefits was presented overall and stratified by age (18-25 vs $26+$ years), sex, and lung disease severity $\left(\mathrm{FEV}_{1} \%\right.$ predicted $\geq 80$ [mild] vs $50-79$ [moderate] vs $<50$ [severe]). The number of pulmonary medications prescribed was compared with patient knowledge of lung function and intended medication benefits. The association between patient knowledge of lung function and medications benefits with self-reported medication adherence was examined both individually and overall for each medication.

Continuous variables were summarized using descriptive statistics such as mean and standard deviation. Differences in means were examined using the parametric Student's $t$-test. Chi-square analysis and the Fisher's exact test (if expected cell counts were $<5$ ) were used to examine categorical variables. The Cochrane-Armitage test was used to examine trends in proportions. Type I error $<0.05$ was considered statistically significant.

To evaluate the robustness of our definitions and classifications, the following sensitivity analyses were performed: 1) widening the range of correct recall of last measured $\mathrm{FEV}_{1} \%$ predicted value to be within $\pm 10 \%, 2$ ) widening the definition of what was considered knowledgeable of medication benefits to knowing most ( $>50 \%)$ as opposed to all $(100 \%)$ of their prescribed medications, and 3) classifying discordant self-reported medication adherence responses as either adherent or non-adherent for individual medications and overall.

\section{Results}

\section{Participants}

A total of 142 out of 167 (85\%) participants approached consented and completed the questionnaires. The remaining 25 patients did not complete the survey due to the following reasons: 1) not interested due to not being prescribed any maintenance pulmonary medications $(n=15) ; 2)$ not interested for unspecified reasons $(n=6) ; 3)$ feeling unwell $(n=1)$; and 4) survey was not submitted after the patient consented $(n=3)$. The characteristics of subjects who did and who did not complete the survey were similar except that the $\mathrm{FEV}_{1} \%$ predicted value was significantly lower for those who did complete the survey (Table 2). The number of patients who took none, one, two, three, and all four pulmonary medications of interest were $12(8 \%), 43(30 \%), 42(30 \%), 34(24 \%)$, and $11(8 \%)$, respectively.

\section{Patient knowledge}

Sixty-four percent of the participants recalled their last measured $\mathrm{FEV}_{1} \%$ predicted value to be within $5 \%$ (Table 3 ). There were no significant differences in knowledge of lung function according to age, sex, lung function categories, or number of medications prescribed.

Knowledge of benefits of dornase alpha, hypertonic saline, inhaled antibiotics, and azithromycin were $68 \%$, $85 \%, 83 \%$, and $89 \%$ respectively. Seventy percent of the participants knew the benefits of all of their prescribed medications. There were no significant differences in knowledge of intended medication benefits according to age, sex, or lung function categories (Table 3). The proportion of patients on four medications who knew all of their benefits was only $36 \%$, whereas the proportion of patients on three, two, or

Table 2 Clinical characteristics of patients who completed and who did not complete the survey

\begin{tabular}{llll}
\hline Patient characteristic & $\begin{array}{l}\text { Patients who } \\
\text { completed } \\
\text { the survey } \\
(\mathbf{n}=\mathbf{I 4 2 )}\end{array}$ & $\begin{array}{l}\text { Patients } \\
\text { who did not } \\
\text { complete the } \\
\text { survey }(\mathbf{n}=\mathbf{2 5})\end{array}$ & P-value \\
\hline Male, \% & $56 \%$ & $57 \%$ & 0.89 \\
Age in years, mean \pm SD & $35 \pm 13$ & $34 \pm 1 \mathrm{I}$ & 0.76 \\
FEV \% predicted, mean \pm SD & $69 \pm 26$ & $94 \pm 28$ & $<0.01$ \\
Number of hospitalizations & $0.57 \pm 1.08$ & $0.48 \pm 1.57$ & 0.79 \\
in the prior year, mean \pm SD & & & \\
\hline
\end{tabular}

Abbreviations: $\mathrm{FEV}_{1} \%$, percent forced expiratory volume in I s; SD, standard deviation. 
Table 3 Patient knowledge of lung function and intended medication benefits

\begin{tabular}{|c|c|c|c|c|}
\hline $\begin{array}{l}\text { Patient } \\
\text { population }\end{array}$ & $\begin{array}{l}\text { Patients } \\
\text { knowledgeable on } \\
\text { FEV } \% \text { within } 5 \%\end{array}$ & $P$-value & $\begin{array}{l}\text { Patients } \\
\text { knowledgeable on all } \\
\text { medication benefits }\end{array}$ & $P$-value \\
\hline All $(n=\mid 42)$ & $64 \%$ & & $70 \%$ & \\
\hline Sex & & 0.82 & & 0.58 \\
\hline Male $(n=8 I)$ & $63 \%$ & & $72 \%$ & \\
\hline Female $(n=59)$ & $68 \%$ & & $66 \%$ & \\
\hline Age in years & & 0.54 & & 0.46 \\
\hline $18-25(n=47)$ & $68 \%$ & & $65 \%$ & \\
\hline$\geq 26(n=92)$ & $63 \%$ & & $73 \%$ & \\
\hline $\mathrm{FEV}_{1} \%$ predicted & & $0.98 *$ & & $0.27^{*}$ \\
\hline$\geq 80 \%(\mathrm{n}=58)$ & $64 \%$ & & $77 \%$ & \\
\hline $50 \%-79 \%(n=48)$ & $67 \%$ & & $66 \%$ & \\
\hline$<50 \%(n=36)$ & $61 \%$ & & $67 \%$ & \\
\hline \multicolumn{2}{|c|}{ Number of pulmonary medications prescribed } & $0.79 *$ & & $0.05^{*}$ \\
\hline $0(n=12)$ & $50 \%$ & & $\mathrm{~N} / \mathrm{A}$ & \\
\hline I $(n=43)$ & $67 \%$ & & $77 \%$ & \\
\hline $2(n=42)$ & $64 \%$ & & $71 \%$ & \\
\hline $3(n=34)$ & $62 \%$ & & $71 \%$ & \\
\hline $4(n=I I)$ & $73 \%$ & & $36 \%$ & \\
\hline
\end{tabular}

Notes: *Cochran-Armitage $P$-value for trend; N/A, not applicable as no pulmonary medications are prescribed.

Abbreviations: FEV,\%, percent forced expiratory volume in I s; SD, standard deviation.

one medication(s) were $71 \%, 71 \%$, and $77 \%$, respectively (Cochran-Armitage $P$-value for trend $=0.05$ ).

Seventy-one percent of participants who were able to recall their last $\mathrm{FEV}_{1} \%$ within $5 \%$ knew the benefits of all of their prescribed medications compared to $69 \%$ for participants who could not recall their last $\mathrm{FEV}_{1} \%$ within $5 \%(P=0.84)$.

\section{Self-reported medication adherence}

A total of 127 out of 142 participants completed the selfreported medication adherence portion of the survey (12 were not prescribed any of the four pulmonary medications of interest and three did not complete the section). The discordance rates for self-reported adherence for individual medications were $17 \%$ for dornase alpha, $11 \%$ for hypertonic saline, $8 \%$ for inhaled antibiotics, and $16 \%$ for azithromycin. Self-reported adherence rate was lowest for hypertonic saline (47\%) but higher for dornase alpha, inhaled antibiotics, and azithromycin $(75 \%, 81 \%$, and $87 \%$, respectively).

For overall medication adherence, 19 of 127 participants (15\%) were categorized as discordant due to discrepant responses for at least half of their prescribed medications. Of the 108 participants with concordant responses, 59 (55\%) were classified as overall adherent and 49 (45\%) as overall non-adherent (Table 4). Age, sex, and lung disease severity were not associated with overall medication adherence. A statistically significant positive linear association was found between the number of prescribed medications and self-reported medication adherence (Cochran-Armitage $P$-value for trend $<0.01)$.

\section{Patient knowledge and self-reported medication adherence}

Fifty-seven percent of participants who could recall their last measured $\mathrm{FEV}_{1} \%$ predicted value to be within $5 \%$ were

Table 4 Self-reported overall medication adherence

\begin{tabular}{lll}
\hline $\begin{array}{l}\text { Patient } \\
\text { population }\end{array}$ & $\begin{array}{l}\text { Proportion of } \\
\text { self-reported } \\
\text { adherence }\end{array}$ & P-value \\
\hline $\begin{array}{l}\text { Overall }(n=108) \\
\text { Sex }\end{array}$ & $55 \%$ & 0.80 \\
$\quad$ Male $(n=62)$ & $54 \%$ & \\
$\quad$ Female $(n=46)$ & $57 \%$ & 0.64 \\
Age in years & & \\
I8-25 $(n=36)$ & $58 \%$ & \\
$\geq 26(n=72)$ & $54 \%$ & $0.42 *$ \\
FEV $\%$ & & \\
$\geq 80 \%(n=38)$ & $50 \%$ & \\
$50 \%-79 \%(n=4 I)$ & $54 \%$ & $<0.0 I^{*}$ \\
$0-49 \%(n=29)$ & $62 \%$ & \\
Number of medications prescribed & \\
I $(n=36)$ & $44 \%$ & \\
$2(n=34)$ & $41 \%$ & \\
$3(n=30)$ & $73 \%$ & \\
$4(n=8)$ & $88 \%$ & \\
\hline
\end{tabular}

Notes: *Cochran-Armitage $P$-value for trend. Patients were considered overall adherent to their medications if they were categorized as adherent to the majority $(>50 \%)$ of their prescribed medications. 
Table 5 Self-reported medication adherence rates versus knowledge of $\mathrm{FEV} \%$ predicted and medication benefits

\begin{tabular}{|c|c|c|c|c|c|}
\hline \multirow[t]{2}{*}{ Knowledge category } & \multicolumn{5}{|c|}{ Proportion of self-reported adherence } \\
\hline & $\begin{array}{l}\text { Overall } \\
(n=108)\end{array}$ & $\begin{array}{l}\text { Dornase } \\
\text { alpha }(n=58)\end{array}$ & $\begin{array}{l}\text { HS } \\
(n=58)\end{array}$ & $\begin{array}{l}\text { Inhaled } \\
\text { antibiotics }(n=47)\end{array}$ & $\begin{array}{l}\text { Azithromycin } \\
(\mathrm{n}=67)\end{array}$ \\
\hline \multicolumn{6}{|l|}{$\mathrm{FEV}, \%$ within $\pm 5 \%$} \\
\hline Yes & $57 \%$ & $84 \%$ & $47 \%$ & $88 \%$ & $84 \%$ \\
\hline No & $50 \%$ & $62 \%$ & $45 \%$ & $64 \%$ & $91 \%$ \\
\hline$P$-value & 0.49 & 0.06 & 0.86 & 0.06 & 0.47 \\
\hline \multicolumn{6}{|l|}{ Benefits of all medications } \\
\hline Yes & $58 \%$ & & & & \\
\hline No & $47 \%$ & & & & \\
\hline$P$-value & 0.30 & & & & \\
\hline \multicolumn{6}{|l|}{ Benefits of dornase alpha } \\
\hline Yes & & $80 \%$ & & & \\
\hline No & & $65 \%$ & & & \\
\hline$P$-value & & 0.20 & & & \\
\hline \multicolumn{6}{|l|}{ Benefits of HS } \\
\hline Yes & & & $46 \%$ & & \\
\hline No & & & $50 \%$ & & \\
\hline$P$-value & & & 0.83 & & \\
\hline \multicolumn{6}{|c|}{ Benefits of inhaled antibiotics } \\
\hline Yes & & & & $82 \%$ & \\
\hline No & & & & $86 \%$ & \\
\hline$P$-value & & & & 0.81 & \\
\hline \multicolumn{6}{|l|}{ Benefits of azithromycin } \\
\hline Yes & & & & & $85 \%$ \\
\hline No & & & & & $100 \%$ \\
\hline$P$-value & & & & & 0.31 \\
\hline
\end{tabular}

Abbreviations: $\mathrm{FEV}, \%$, percent forced expiratory volume in I s; HS, hypertonic saline.

overall adherent to their pulmonary medications compared to $50 \%$ of those who could not recall $(P=0.49$; Table 5$)$. Participants who knew their lung function self-reported higher adherence to dornase alpha $(84 \%$ vs $62 \%, P=0.06)$ and inhaled antibiotics ( $88 \%$ vs $64 \%, P=0.06)$ compared to those who did not know their lung function, but these associations were not statistically significant.

Participants who knew the benefits of all of their prescribed medications were not significantly more likely to be overall adherent to their medications by self-report compared to those who did not ( $58 \%$ vs $47 \%, P=0.30$, Table 5 ). There was no association between knowledge of medication benefits and self-reported adherence to the individual medications of interest.

\section{Sensitivity analysis}

A sensitivity analysis was conducted examining a more relaxed definition of patient knowledge of lung function (ie recall of last $\mathrm{FEV}_{1} \%$ within 10\%) and there was no significant association with individual or overall self-reported medication adherence (all $P>0.05$ ). In a sensitivity analysis classifying patients who knew most $(>50 \%)$ of their medication benefits as knowledgeable, as opposed to all $(100 \%)$ of the benefits, there was no significant difference in overall medication adherence between subjects who were and those who were not knowledgeable $(P=0.33)$. Finally, a sensitivity analysis was performed classifying patients with discordant adherence responses into either adherent or non-adherent groups. Regardless of the grouping, this discordant population did not significantly alter the results examining the associations between knowledge and selfreported adherence.

\section{Discussion}

The primary motivation of this study was to determine if knowledge gaps were contributing to the low rates of adherence observed in our adult CF population. We hypothesized that patients with less lung disease and less treatment-related knowledge were less likely to be engaged and adherent to their prescribed medications. This is supported in the literature in case of other respiratory diseases such as asthma and chronic obstructive pulmonary disease, whereby lack of knowledge has been identified as a barrier to medication adherence and disease management. ${ }^{18,19}$ In contrast, education 
and knowledge has not been consistently associated with medication adherence in other chronic conditions..$^{20,21}$

Contrary to our hypothesis, the results of this study demonstrated no significant association between patient knowledge of lung function or intended medication benefits and self-reported adherence. This is likely because adherence is a complex construct including not only the perception of one's own health and treatment efficacy but also other psychosocial factors. Our results support the findings from systematic reviews of non-CF chronic conditions that demonstrate inconsistent improvements in adherence following educational interventions targeted at improving adherence. ${ }^{22,23}$ Programs aimed at educating patients about their chronic disease and medications were found to have little to no impact on medication adherence, even when their knowledge improved. ${ }^{20,21}$

While knowledge may influence medication adherence to some degree, other factors likely play a greater role in governing adherence. Depression, for example, has recently been linked to decreased medication adherence in CF patients. ${ }^{24}$ In addition, parental depression has been associated with poor medication adherence in their CF offspring. ${ }^{25}$ Low socioeconomic status is another significant factor associated with worse adherence to airway clearance therapy in $\mathrm{CF}^{26}$ and inhaled steroid therapy in asthma ${ }^{27}$ but has not been clearly demonstrated with respiratory medications in $\mathrm{CF} .{ }^{28}$ Due to the anonymous nature of data collection in this study, these variables could not been compared to self-reported adherence to pulmonary medications. Other factors influencing adherence in CF such as treatment burden, time, forgetfulness, fatigue, stigma, and embarrassment have also been cited and likely play important roles. ${ }^{6-12}$ From our experience, non-adherence is often complex and all of these factors can contribute to non-adherence, leading to high rates of nonadherence reported in this study.

Prior studies have demonstrated that age is associated with medication adherence, with worsening rates of compliance in adolescence..$^{4,5,12,29}$ In our study, age was not found to be significantly associated with self-reported adherence. This may be because the two age groups that were compared were younger and older adults, but in other studies, comparison was between children, adolescents, and adults. Our results also show that patients taking a greater number of medications had higher self-reported adherences rates, consistent with prior literature. ${ }^{6}$ Patients who are already believed to be adherent to medications are more likely to be prescribed additional medications. As hypothesized by Quittner et al, ${ }^{6}$ it may also be that patients who have more severe disease have greater treatment complexity and are thus more likely to adhere with medications. Our study also demonstrates this trend, that is, patients with worse disease reported higher adherence.

While our study sample was a convenience sample enrolled from a single large adult $\mathrm{CF}$ clinic, we believe that our findings are representative of the general adult CF population as St Paul Hospital's Adult CF Clinic provides care to adult $\mathrm{CF}$ patients from the entire mainland region of British Columbia. The sample size of 142 adult patients represents the majority of the patient base taking maintenance pulmonary medications.

\section{Limitations}

One potential limitation of our study is the significantly higher $\mathrm{FEV}_{1} \%$ predicted value of non-participants compared with participants (Table 2). This is expected as patients with normal lung function are less likely to be prescribed maintenance pulmonary medications and thus participate in the study. Chart review also revealed that participants and non-participants were of similar demographic characteristics, which, along with the high recruitment rate of $85 \%$, gives us confidence that the results of this study can be generalized to the CF clinic population currently on pulmonary medications.

Another potential limitation is classifying whether a patient is truly knowledgeable based on their ability to recall their most recent $\mathrm{FEV}_{1} \%$ predicted value or the intended benefits of their prescribed medications. Patient knowledge of their $\mathrm{FEV}_{1} \%$ value was chosen as a marker of self-awareness of lung function and disease severity as this measurement is reported and discussed with the patient during attendance at CF clinic (approximately every three to four months), similar to knowledge of recent hemoglobin A1c in diabetes ${ }^{30}$ and $\mathrm{FEV}_{1} \%$ in COPD. ${ }^{31}$ Recall of lung function, however, could be more likely to be correct if the patient was last seen more recently. While our knowledge questionnaires have not been validated previously, we believe our results are reliable, as the instructions and multiple-choice items were intuitive, selfexplanatory, and probed specific knowledge components.

Another important consideration is that adherence was measured based on self-report that often overestimates actual adherence, although our self-reported adherence rates do fall within the range reported in the literature using objective measures of adherence. ${ }^{2-4}$ A study of adherence to dornase alpha in adult $\mathrm{CF}$ patients showed a self-reported adherence rate of $82 \%$, which is comparable to the adherence rate of $75 \%$ in this study. ${ }^{2}$ In a pediatric study on CF, approximately $90 \%$ of parents and $78 \%$ of children self-reported adherence to dornase alpha, with adherence rates of $57 \%$ and $72 \%$ by 
diary and pharmacy history, respectively. ${ }^{3}$ Another study in children and adolescents using electronic monitoring of adherence reported an adherence rate of $67 \%$ to dornase alpha. ${ }^{4}$ Similarly, self-reported adherence to inhaled tobramycin was $85 \%$ in a pediatric study ${ }^{3}$ compared to $81 \%$ to inhaled antibiotics in this study. Reasons for misclassification of adherence groups include guessing or deliberately misrepresenting their adherence because they are unsure or want to appease their health care providers. This was minimized by having the "not sure" option, asking about adherence in two ways for response consistency and by informing participants that their responses were anonymous to their health care providers. Nevertheless, this suggests the need for the self-reported results to be validated by other records, such as pharmacy dispensing records, diary data, and electronic monitors. ${ }^{3}$

\section{Conclusion}

In conclusion, our results found no significant associations between patient knowledge and self-reported adherence in adults with CF. While optimizing disease and treatmentrelated knowledge is clearly important, filling gaps in knowledge may not have the anticipated benefit of improving medication adherence in the adult setting. Other factors (eg, psychosocial and lack of time) likely play more important roles in medication adherence and should be targeted in future interventional strategies to optimize medication adherence.

\section{Acknowledgments}

We would like to thank our patients for their enthusiastic participation and would like to acknowledge Stephanie Maganja, Eri Flores, and Eric Park for their help in patient recruitment and data entry, as well as other members of the Adult Cystic Fibrosis Clinic at St Paul's Hospital for their support. We would also like to acknowledge the University of British Columbia, Faculty of Medicine's Summer Student Research Program, and Cystic Fibrosis Canada for funding this research.

Ann Hsu-An Lin was supported by the Summer Student Research Program (SSRP) by the Faculty of Medicine, University of British Columbia, and the Canadian Institute of Health Research (CIHR) Health Professional Research Award. Bradley S Quon was supported by a Cystic Fibrosis Canada Clinician-Scientist Award and operating grants from the BC Lung Association and Cystic Fibrosis Canada, but the funding agencies played no role in this work.

\section{Disclosure}

The authors report no conflicts of interest in this work.

\section{References}

1. Flume PA, O'Sullivan BP, Robinson KA, et al. Cystic fibrosis pulmonary guidelines: chronic medications for maintenance of lung health. Am J Respir Crit Care Med. 2007;176(10):957-969.

2. Burrows JA, Bunting JP, Masel PJ, Bell SC. Nebulised dornase alpha: adherence in adults with cystic fibrosis. $J$ Cyst Fibros. 2002;1(4): $255-259$.

3. Modi AC, Lim CS, Yu N, Geller D, Wagner MH, Quittner AL. A multimethod assessment of treatment adherence for children with cystic fibrosis. J Cyst Fibros. 2006;5(3):177-185.

4. Zindani GN, Streetman DD, Streetman DS, Nasr SZ. Adherence to treatment in children and adolescent patients with cystic fibrosis. J Adolesc Health. 2006;38(1):13-17.

5. Eakin MN, Bilderback A, Boyle MP, Mogayzel PJ, Riekert KA. Longitudinal association between medication adherence and lung health in people with cystic fibrosis. J Cyst Fibros. 2011;10(4):258-264.

6. Quittner AL, Zhang J, Marynchenko M, et al. Pulmonary medication adherence and health-care use in cystic fibrosis. Chest. 2014;146(1): $142-151$.

7. Conway SP, Pond MN, Hamnett T, Watson A. Compliance with treatment in adult patients with cystic fibrosis. Thorax. 1996;51(1):29-33.

8. George M, Rand-Giovannetti D, Eakin MN, Borrelli B, Zettler M, Riekert KA. Perceptions of barriers and facilitators: self-management decisions by older adolescents and adults with CF. J Cyst Fibros. 2010; 9(6):425-432.

9. Dziuban EJ, Saab-Abazeed L, Chaudhry SR, Streetman DS, Nasr SZ. Identifying barriers to treatment adherence and related attitudinal patterns in adolescents with cystic fibrosis. Pediatr Pulmonol. 2010;45(5): 450-458.

10. Bucks RS, Hawkins K, Skinner TC, Horn S, Seddon P, Horne R. Adherence to treatment in adolescents with cystic fibrosis: the role of illness perceptions and treatment beliefs. JPediatr Psychol. 2009;34(8): 893-902.

11. Latchford G, Duff A, Quinn J, Conway S, Conner M. Adherence to nebulised antibiotics in cystic fibrosis. Patient Educ Couns. 2009;75(1): 141-144.

12. Daniels T, Goodacre L, Sutton C, Pollard K, Conway S, Peckham D. Accurate assessment of adherence: self-report and clinician report vs electronic monitoring of nebulizers. Chest. 2011;140(2):425-432.

13. Ievers CE, Brown RT, Drotar D, Caplan D, Pishevar BS, Lambert RG. Knowledge of physician prescriptions and adherence to treatment among children with cystic fibrosis and their mothers. $J$ Dev Behav Pediatr. 1999;20(5):335-343.

14. Balfour L, Armstrong M, Holly C, et al. Development and psychometric validation of a cystic fibrosis knowledge scale. Respirology. 2014; 19:1209-1214.

15. Farrell PM, Rosenstein BJ, White TB, et al. Guidelines for diagnosis of cystic fibrosis in newborns through older adults: Cystic Fibrosis Foundation consensus report. J Pediatr. 2008;153(2):S4-S14.

16. McNamara PS, McCormack P, McDonald AJ, Heaf L, Southern KW. Open adherence monitoring using routine data download from an adaptive aerosol delivery nebuliser in children with cystic fibrosis. $J$ Cyst Fibros. 2009;8(4):258-263.

17. Karve S, Cleves MA, Helm M, Hudson TJ, West DS, Martin BC. Good and poor adherence: optimal cut-point for adherence measures using administrative claims data. Curr Med Res Opin. 2009;25(9): 2303-2310.

18. Mäkelä MJ, Backer V, Hedegaard M, Larsson K. Adherence to inhaled therapies, health outcomes and costs in patients with asthma and COPD Respir Med. 2013;107(10):1481-1490.

19. Lakhanpaul M, Bird D, Manikam L, et al. A systematic review of explanatory factors of barriers and facilitators to improving asthma management in South Asian children. BMC Public Health. 2014;14:403.

20. Amado GE, Pujol RE, Pacheco HV, Borras JM; ADIEHTA Group. Knowledge and adherence to antihypertensive therapy in primary care: results of a randomized trial. Gac Sanit. 2011;25(1):62-67. 
21. Chen AMH, Yehle KS, Albert NM, et al. Relationships between health literacy and heart failure knowledge, self-efficacy, and self-care adherence. Res Social Adm Pharm. 2014;10(2):378-386.

22. Kripalani S, Yao X, Haynes RB. Interventions to enhance medication adherence in chronic medical conditions: a systematic review. Arch Intern Med. 2007;167(6):540-550.

23. Nieuwlaat R, Wilczynski N, Navarro T, et al. Interventions for enhancing medication adherence. Cochrane Database Syst Rev. 2014; 11:CD000011.

24. Hilliard ME, Eakin MN, Borrelli B, Green A, Riekert KA. Medication beliefs mediate between depressive symptoms and medication adherence in cystic fibrosis. Health Psychol. 2015;34(5):496-504.

25. Barker DH, Quittner AL. Parental depression and pancreatic enzymes adherence in children with cystic fibrosis. Pediatrics. 2016;137(2): e20152296.

26. Oates GR, Stepanikova I, Gamble S, Gutierrez HH, Harris WT. Adherence to airway clearance therapy in pediatric cystic fibrosis: Socioeconomic factors and respiratory outcomes. Pediatr Pulmonol. 2015;50(12):1244-1252.
27. Apter AJ, Reisine ST, Affleck G, Barrows E, ZuWallack RL. Adherence with twice-daily dosing of inhaled steroids. Socioeconomic and healthbelief differences. Am J Respir Crit Care Med. 1998;157(6 Pt 1): 1810-1817.

28. Pendleton DA, David TJ. The compliance conundrum in cystic fibrosis. $J$ R Soc Med. 2000;93:9-13.

29. Arias Llorente RP, Bousono Garcia C, Diaz Martin JJ. Treatment compliance in children and adults with cystic fibrosis. J Cyst Fibros. 2008; 7(5):359-367.

30. Heisler M, Piette JD, Spencer M, Kieffer E, Vijan S. The relationship between knowledge of recent $\mathrm{HbA1c}$ values and diabetes care understanding and self-management. Diabetes Care. 2005;28(4):816-822.

31. Barr RG, Celli BR, Mannino DM, et al. Comorbidities, patient knowledge, and disease management in a national sample of patients with COPD. Am J Med. 2009;122(4):348-355.

\section{Publish your work in this journal}

Patient Preference and Adherence is an international, peer-reviewed, open access journal that focuses on the growing importance of patient preference and adherence throughout the therapeutic continuum. Patient satisfaction, acceptability, quality of life, compliance, persistence and their role in developing new therapeutic modalities and compounds to optimize clinical outcomes for existing disease states are major areas of interest for the journal. This journal has been accepted for indexing on PubMed Central. The manuscript management system is completely online and includes a very quick and fair peer-review system, which is all easy to use. Visit http://www. dovepress.com/testimonials.php to read real quotes from published authors. 